\title{
Testing a Model of Stress and Health Using Meta-Analytic Path Analysis
}

\author{
Lifa Yu • Chao-Hung Chiu* • Yaw-Sheng Lin** \\ Hsiu-Hung Wang*** • Jew-Wu Chen****
}

\begin{abstract}
The goal of this study was to use meta-analytic path analysis to evaluate a theoretical model of stress and health. A meta-analysis technique was adopted to combine and re-analyze 477 studies that investigated stress-related topics between January 1980 and December 2003 in Taiwan. Databases searched included PerioPath-Index to Chinese Periodical Literature, Electronic Theses and Dissertations System, and NSC (National Science Council) Science and Technology Information System. Variables recorded included stress, health, social support, coping strategies, and personality traits. A correlation matrix of these variables was derived from meta-analytic data and then analyzed using structural path analysis to test the fitness of the hypothesized stress-health model to the observed aggregated data. Results showed the revised hypothesized model to be a reasonable, good fit to aggregated data. Based on the theoretical stress-health model developed in this study, subjective stress was found to have a substantively important and direct effect on health, whereas objective stress required the mediating function of subjective stress to exercise an influence on health. Such variables as social support, coping strategies, and personality traits had comparatively weaker influences, either direct or indirect, on the stress-health process. This study provided a holistic view on the relationship between stress and health in the context of stress and proposed a direction for future research and practice.
\end{abstract}

Key Words: stress, health, meta-analysis, path analysis.

\section{Introduction}

Numerous studies have been done on the relationship between stress and health. Sarafino (2006) contended that stress influenced behavior as well as the physical and psychological condition. Hammer, Saksvik, Nytro, Torvatn, and Bayazit (2004) pointed out that a negative correlation existed between stress and job performance and job satisfaction, respectively. Similarly, Chu and Kao (2005) found that people under high pressure were apt to be nervous and anxious (psychological aspect), prone to headaches, high blood pressure and heart attacks (physical aspect) and prone to absenteeism, high rates of quitting jobs, and low productivity (behavioral aspect). Many other research findings also found the existence, to varying degrees, of a rela- tionship between stress and health (Dahlin, Joneborg, \& Runeson, 2005; Ng \& Jeffery, 2003).

Pearlin (1999) and Lu (1997), reviewing previous studies, pointed out that certain variables play moderating roles in the relationship between stress and health. Lu further noted that some of the variables between stressors (objective stress) and health played not only a moderating but a mediating role and that subjective stress was the mediating factor necessary to link objective stress and health. As Cox (1978) stated, the objective event itself was not important. What was important was that, after appraising a situation, whether or not an individual felt that the demands of such were beyond his/her ability to cope. Lazarus and Folkman (1984) further indicated that after appraising an event to be stressful, an individual would assess whether

PhD, Associate Professor, College of Health Science, Kaohsiung Medical University; *MS, Lecturer, Students Counseling Center, Far East University; **PhD, Associate Professor, Department of Clinical and Counseling Psychology, National Dong Hwa University; ***PhD, Professor, College of Nursing, Kaohsiung Medical University; ****PhD, Associate Professor, College of Health Science.

Received: August 16, 2006 Revised: March 7, 2007 Accepted: June 20, 2007

Address correspondence to: Jew-Wu Chen, No. 100, Shih-Chuan 1st Rd., Kaohsiung 80708, Taiwan, ROC. Tel: 886(7)321-7997 ext. 19; Fax: 886(7)321-7997; E-mail: jwchen@kmu.edu.tw 
available resources were sufficient to meet event demands. Some studies investigating both subjective and objective stresses and comparing their predictive powers found that objective stress was a more powerful predictor, while other studies obtained opposite results indicating that subjective stress was more closely related to health (Jiang, 1991; Lue, Chen, \& Kao, 2006). From the perspective of viewing stress as a stimulus, objective stress directly influences our health. However, from the perspective of viewing stress as an interactive process, objective stress requires the mediating function of subjective stress to exercise an influence on health (Ogden, 2004). In other words, it is assumed that objective stress affects our health through two channels: direct and indirect. In order to clarify the role that subjective stress plays in the entire stress process, it is necessary to classify stress into objective stress and subjective stress.

Moderating/mediating variables between stress and health that have been discussed the most include subjective stress, coping strategies, social support, and personality traits (Sarafino, 2006). These are still regularly researched (Ding, 2003; Diong et al., 2005).

Coping strategies are the methods or behaviors that one adopts to handle a specific situation in which one has appraised and felt the burden of external events and internal needs (Lazarus \& Folkman, 1984). In other words, coping strategies are adopted after subjective stress arises. Coping strategies are classified into emotion-focused and problem-focused coping strategies. The former is aimed at regulating or controlling the person's emotional response to stress, whereas the latter is aimed at reducing the demands of stressors or expanding the resources to deal with them. Studies have shown that different coping strategies result in different health conditions under stressful situations (Aneshensel, 1999; Cheng, Dai, Kuo, \& Yao, 2000).

As for social support, Cohen and Wills (1985) contended that in the stress-health process, social support will intervene in two contexts: (a) when one is in the process of appraising if he has enough resources to meet the demands of a stressful situation, and (b) when one is in the process of coping with a stressful situation. Based on this viewpoint, social support will directly influence one's subjective stress and coping strategies. Cohen and Wills reexamined the previous studies that investigated the effects of social support on health and found research support for both the main-effects and buffering models. This suggests that social support may either directly influence our health or indirectly influence our health through other channels or routes. Recent studies also support the role of both direct (Liaw, Cheng, \& Wang, 2005) and indirect influences (Karlin, Brondolo, \& Schwartz, 2003).

Regarding personality traits, some scholars pointed out that personality traits influence one's viewpoints on events and further influence one's subjective stress (Ding, 2003; Sarafino, 2006). For example, Sarafino (2006) indicated that people with a Type A personality often regard a stressful life event as a threat to their personal control. People who have an internal locus of control (named as internal-control personality hereafter) believe themselves able to exercise an influence on the outcome of events and, therefore, do their best to search for possible means of control. As a result, they would experience and sense stress less. However, people who have an external locus of control ('external-control personality' hereafter) would attribute their successes to luck and attribute failures to the influence of others. Because this latter group do not think they can control their own destiny, they would not do their best to reduce stress and, therefore, feel helpless easily (Sarafino, 2006). Some studies have found that personality traits directly affect health and some studies did not (Ding, 2003; Wasylkiw \& Fekken, 2002). Other studies revealed that personality traits might affect one's health through coping strategies. In other words, health is affected by coping strategies, which were adopted due to personality (Matthews et al., 2006; Mills, 2000).

Researchers focused on the relationships among these variables and tried to link theory and empirical data in the hope that theory could be verified through empirical studies. Structural equation modeling (SEM) is a technique used to verify theoretical causal models that has been used often recently. In primary studies, verifying a rich or complex theoretical model is not an easy task because it is difficult to take into account all potential theoretical dimensions. However, using techniques that combine psychometric meta-analysis and structural equation modeling to gather and reanalyze all primary study data will provide a powerful means for testing broader, richer, and more complex theories that are unlikely to be feasibly tested in any one single primary study (Viswesvaran \& Ones, 1995). Hunter and Schmidt (2004) also suggested that metaanalysis may be employed in theory development by using aggregated study effect sizes to test causal models. Metaanalysis is a quantitative method used to combine results from multiple primary studies. Structural equation modeling for path analysis is a method that employs simple bi- 
variate correlations to estimate the relationships in a system of structural equations.

In order to further investigate the roles that objective stress, subjective stress, social support, coping strategies, and personality traits play in the relationship between stress and health, this study proposes a theoretical stresshealth model based on previous theories and research findings (see Figure 1) that, it is hoped, can be verified by empirical research data gathered in the context of stress. This study employed the meta-analytic path analysis technique to test the proposed hypothesized model and hoped to obtain a holistic perspective on the relationship between stress and health and, further, to propose a direction for future research and practice.

\section{Methods}

Methods used were based on the procedures outlined by Viswesvaran and Ones (1995). Two basic steps were involved. The first step was to conduct meta-analyses to produce a matrix of correlations among all variables (or constructs) of interest. The second step was to apply path analysis to analyze the meta-analytic correlation matrix.
The advantage of combining meta-analysis and path analysis in theory testing is that not all relationships specified by a theory need to be included in each primary study (Viswesvaran \& Ones, 1995).

\section{Conceptualization and Classification of Stress and Health Constructs}

Stress and health are multidimensional constructs (Wang, Wu, \& Liu, 2003; Wheaton, 1999). As for stress, this current study combined various kinds of stress types, such as caregivers' stress, stress of military service, disaster stress, work stress, practicum stress, illness stress, stress of students' life, and so on. All these various stress types were classified according to the contexts in which different life events occurred. Because of the specific purpose of our study, stress was further classified into objective stress and subjective stress. The objective, external forces or events that affect the individual, such as disasters, major life events, or daily hassles, are defined as objective stress, whereas the individual's subjective cognition and feelings caused by such events are defined as subjective stress.

As for health, our study adopted Smith's (1981) health construct in terms of clinical, adaptive, role-performance,

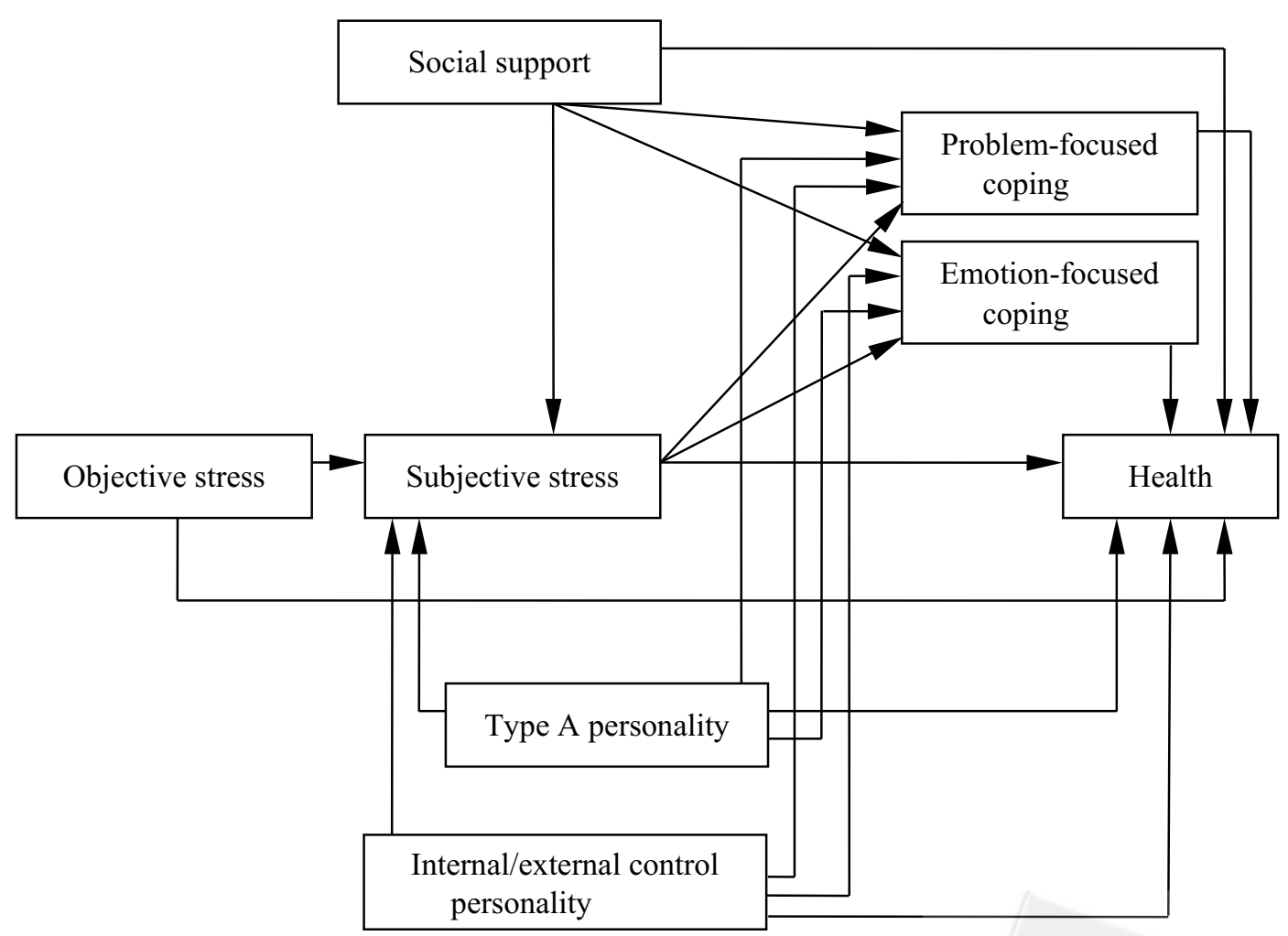

Figure 1. The proposed path diagram for the theoretical stress-health model. 
and eudemonistic facets. The clinical facet addresses the presence or absence of signs or symptoms of disease or disability in the individual as identified by medical science. The adaptive facet is concerned with the extent to which the individual is able to adapt flexibly to his/her environment. The role-performance facet is concerned with the degree to which an individual performs his/her social role and achieves an expected output. The eudemonistic facet addresses the degree of exuberant well-being and satisfaction felt by the individual. In this current study, stomachache, hypertension, depression, anxiety and so forth were categorized as clinical variables. Health behavior, social behavior, self-esteem, deviated behavior and so forth were categorized as adaptive variables. Job involvement, organizational commitment, job burnout, intent of leave, and so forth were categorized as role-performance variables. Job satisfaction, life satisfaction, quality of life and so forth were categorized as eudemonistic variables. All the above four facets were combined into a general construct of health in our study.

\section{Literature Search}

A computerized literature search was carried out to search for primary studies done on stress published between January 1980 and December 2003 in Taiwan on the following databases: PerioPath--Index to Chinese Periodical Literature, Electronic Theses and Dissertations System, and NSC (National Science Council) Science and Technology Information System. Keywords/titles used to identify relevant studies included "stress" and "life event". Our search was restricted to studies published in Chinese and involving human subjects. In addition, we followed up on references cited in identified studies to locate additional studies.

Three inclusion criteria were adopted in this metaanalysis. First, primary studies must examine relationships between at least two of the following eight variables: stress (objective stress or subjective stress), health, social support, coping strategies (problem-focused coping or emotion-focused coping) and personality traits (Type A personality or internal/external control personality). Second, they must provide information sufficient to compute effect sizes. Third, where duplicate studies were found, those that could provide the most comprehensive and necessary information were selected. In our preliminary literature search, 722 dissertation and thesis and 746 research article abstracts were identified and reviewed. Of these 1,468 studies, 477 studies ( 377 dissertations and theses and 100 research articles) met inclusion criteria and were included in our meta-analysis employed to calculate meta-analytic estimates. (A list of these 477 primary studies is available from the corresponding author upon request.)

\section{Intercoder Reliability}

We examined all collected primary studies and recoded information on each study's demographic and substantive features. To ensure literature search process reliability, at the preliminary search stage, approximately one-hundred studies were randomly selected from the total pool of 1,468 studies and read independently by one of the authors and a second coder, respectively, to judge metaanalysis inclusion eligibility based on established study criteria. The trained second coder holds a master's degree in clinical psychology and is a licensed clinician. Intercoder agreement was $98 \%$. As for the classification of the eight variables of interest, forty-eight studies (about 10\%) were randomly drawn from the final set of 477 studies and independently coded by the same coders. Intercoder agreement for this set of forty-eight studies was $100 \%$ for objective-subjective stress, $98 \%$ for social support, $96 \%$ for problem-focused coping strategies, $98 \%$ for emotionfocused coping strategies, 100\% for Type A and internal/ external control personalities, $96 \%$ to $100 \%$ for categorization of health facets. Disagreements in coding were resolved through discussion.

\section{Meta-Analytic Procedure}

The correlation coefficient was the effect size estimate used in our meta-analysis. Correlation coefficients between pairs of the eight variables (objective stress, subjective stress, health, social support, problem-focused coping strategies, emotion-focused coping strategies, Type A personality, and internal/external control personality) were aggregated across studies. We used Hedges and Olkin's (1985) meta-analysis procedure to determine the average correlation for each of the pairwise relationships between these eight variables. At this meta-analysis stage, we first transformed all correlations to Fisher's $Z_{\mathrm{r}}$ correlations to reduce the effects of sampling distribution non-normality. When more than one Fisher's $Z_{\mathrm{r}}$ correlation was available for the same pair of variables in a single study, they were averaged together. Second, we weighted each Fisher's $\mathrm{Z}_{\mathrm{r}}$ correlation by sample size in order to correct for sampling error, and computed the average sample-size weighted Fisher $Z_{\mathrm{r}}$ correlation for each pair of these eight variables. 
Finally, we transformed the average weighted Fisher's $Z_{r}$ correlation for each pair of the eight variables back to the standard correlational form for ease of interpretation. This resulted in a matrix of meta-analytic correlations between these eight variables. The Comprehensive Meta-Analysis computer program (Borenstein, Hedges, Higgins, \& Rothstein, 2005) was used to perform data analysis.

\section{Path Analysis}

At this stage, a proposed path model based on metaanalytic data was estimated. We examined this proposed path model in the current study by constructing a matrix of meta-analytically derived correlations consisting of pairwise relationships among the eight variables of interest. We performed path analysis on the resulting correlation matrix by using LISREL 8.7 (Jöreskog \& Sörbom, 2004) to obtain path coefficients and tests of model fit. For model sample size, we chose to use the harmonic mean of matrix sample sizes as suggested by Viswesvaran and Ones (1995). In our study, the harmonic mean was large $(N=4,745)$. This choice of $N$ was in line with the logic of meta-analysis as a data-pooling enterprise, which provided a very sensitive test of the goodness of model fit and the significance of structural model paths. On the basis of recommendations by Hu and Bentler (1999), we evaluated model fit using the standardized root mean squared residual (SRMR), the root mean squared error of approximation (RMSEA), the nonnormed fit index (NNFI), the incremental fit index (IFI), the relative noncentrality index (RNI), the comparative fit index (CFI) and the standard chi-square statistic. Hu and Bentler recommended that values of less than or equal to .08 for SRMR and .06 for RMSEA, and greater than or equal to .95 for NNFI, IFI, RNI and CFI be used as cutoffs to represent a good fit of a model to data.

\section{Results}

Basic characteristics of the 477 studies included in this meta-analytic path analysis are described as follows: $18.66 \%$ were published between $1980-1990,54.72 \%$ between 1991-2000, and 26.62\% between 2001-2003. Most (79.04\%) were dissertations or master's theses and 20.96\% were journal articles. In terms of researchers' specialty or training, $22.85 \%$ were in the field of education, $18.87 \%$ were in nursing, $18.03 \%$ were in management, $16.56 \%$ were in psychology and counseling, $8.39 \%$ were in social work, $6.08 \%$ were in medicine and public health, and $9.22 \%$ were in other fields. In terms of ages targeted in studies, $12.79 \%$ targeted subjects under $18,19.71 \%$ targeted those between 19-30, 16.35\% targeted those between 31-45, 6.92\% targeted subjects over 46 , and $44.23 \%$ targeted subjects in a broad age range. Female samples were used exclusively in $21.8 \%$ of studies, while $4.6 \%$ targeted male samples only, $69.6 \%$ targeted mixed samples, and $4 \%$ were unspecified. Nearly half (44.23\%) studied married samples, $29.14 \%$ studied unmarried samples and $20 \%$ used mixed samples. Over half (53.25\%) targeted subjects educated at least to the college level, $35.01 \%$ targeted subjects with high school diplomas or below, and $11.74 \%$ targeted sample groups with various levels of education.

Table 1 presents the meta-analyzed correlations among eight variables, along with the number of primary studies and the total sample size contributing to each of the correlations. Most (24 out of 28) of the average weighted correlations $\left(r_{+}\right)$in Table 1 were significantly different from zero $(p<.001)$. The sample sizes used to estimate each correlation in Table 1 ranged from 720 to 84,387 , and the number of studies ranged from 1 to 187 . The correlation between subjective stress and health, based on the largest sample size, represented the most precise correlation. The least precise correlation, based on the smallest sample size, was that between social support and Type A personality. In accordance with Cohen's guidelines (as cited in Lipsey \& Wilson, 2001) for small ( $r \leq .10)$, medium $(r=.25)$ and large effects $(r \geq .40)$, among the 28 average weighted correlations obtained in this meta-analysis, a majority of correlations (18 out of 28) had effect levels that measured between "small" and "medium" $\left(.107 \leq r_{+} \leq .377\right)$. One correlation registered an exceptionally high effect level $\left(r_{+}\right.$ $=.726$ ). However, model testing by path analysis, rather than meta-analyses of associations between any two of the eight variables, represents the main concern of this paper. Please refer to the Kaohsiung Journal of Medical Sciences 2007 [23(6), 289-299] for detailed results of this metaanalysis of the relationship between stress and health.

The result of the initial path analysis showed that although most fit indices met the criteria for model fit $(\mathrm{SRMR}=.019 ; \mathrm{IFI}=.98 ; \mathrm{RNI}=.98 ; \mathrm{CFI}=.98)$, some fell short of the recommended cutoff criteria. The chi-square test for this model was significant, $\chi^{2}(3, N=4,745)=$ $102.81, p<.001$, and two fit indices did not indicate a good model fit $(\mathrm{RMSEA}=.081 ; \mathrm{NNFI}=.84)$, and five path coefficients ( $\beta$, standardized regression coefficients) were not significant. Taking into consideration the parsimonious 
Table 1.

Summary of Meta-Analysis Results for Average Weighted Correlations

\begin{tabular}{|c|c|c|c|c|c|c|c|c|}
\hline Variable & 1 & 2 & 3 & 4 & 5 & 6 & 7 & 8 \\
\hline Objective stress & - & & & & & & & \\
\hline \multirow[t]{3}{*}{ Subjective stress } & .726 & & & & & & & \\
\hline & 27 & - & & & & & & \\
\hline & 11,522 & & & & & & & \\
\hline \multirow[t]{3}{*}{ Health $^{a}$} & .300 & .377 & & & & & & \\
\hline & 99 & 187 & - & & & & & \\
\hline & 49,818 & 84,387 & & & & & & \\
\hline \multirow[t]{3}{*}{ Social support } & -.137 & -.107 & -.129 & & & & & \\
\hline & 29 & 74 & 95 & - & & & & \\
\hline & 17,652 & 30,820 & 54,786 & & & & & \\
\hline \multirow[t]{3}{*}{ Problem-focused coping } & -.079 & -.026 & -.099 & .293 & & & & \\
\hline & 22 & 78 & 78 & 23 & - & & & \\
\hline & 12,933 & 35,361 & 35,216 & 8,285 & & & & \\
\hline \multirow[t]{3}{*}{ Emotion-focused coping } & .161 & .161 & .138 & .094 & .123 & & & \\
\hline & 21 & 79 & 76 & 20 & 28 & - & & \\
\hline & 11,610 & 34,967 & 34,352 & 6,916 & 14,394 & & & \\
\hline \multirow[t]{3}{*}{ Type A personality } & .164 & .187 & .082 & $.064 \dagger$ & $.008 \dagger$ & .155 & & \\
\hline & 7 & 11 & 41 & 1 & 5 & 5 & - & \\
\hline & 1,748 & 3,056 & 15,787 & 720 & 1,860 & 1,860 & & \\
\hline \multirow[t]{3}{*}{ Internal/external control personality ${ }^{\mathrm{b}}$} & .107 & .141 & .178 & -.164 & -.244 & $.004 \dagger$ & $.027 \dagger$ & \\
\hline & 11 & 24 & 41 & 5 & 13 & 12 & 7 & - \\
\hline & 4,790 & 10,606 & 18,506 & 1,654 & 6,859 & 6,302 & 2,706 & \\
\hline
\end{tabular}

Note. The first value of each variable entry represents the average weighted correlation; the second represents the number of studies and the third represents total sample size. All correlations, except those marked by a dagger, are significant at $p<.001$.

${ }^{\mathrm{a}}$ The higher the health score, the poorer the health condition. ${ }^{\mathrm{b}}$ The higher the internal/external control personality score, the higher the tendency toward external control.

principle, we removed the five paths with nonsignificant standardized regression coefficients and reran the same analysis. The five paths we removed were the paths from Type A personality to health, from Type A personality to problem-focused coping strategies, from internal/external control personality to emotion-focused coping strategies, from social support to subjective stress, and from objective stress to health. This resulted in a significant increase in model fit for the revised model. The result is presented in Figure 2. Given the large sample size used in the analysis, the chi-square test for the revised model was still significant, $\chi^{2}(8, N=4,745)=105.99, p<.001$, but the model demonstrated a good fit to data (RMSEA $=$ $.049 ;$ SRMR $=.020 ; \mathrm{IFI}=.98 ; \mathrm{RNI}=.98 ; \mathrm{CFI}=.98)$. Even the NNFI value (.94) was also very close to $\mathrm{Hu}$ and Bentler's (1999) recommended cutoff. On the whole, the revised model demonstrated a reasonably good fit to aggregated data.

The revised model was also re-estimated based on the disattenuated correlation matrix, which was obtained from correction for measurement error caused by imperfect reliability of measures or variables (Hunter \& Schmidt, 2004). The result, although path coefficients were slightly higher, was similar to that obtained using the original correlation matrix. Because a large composite sample size $(N=4,745)$ was used in the analysis, path analysis would have led to highly statistically significant results across the board. Therefore, we re-estimated the revised model based on the original correlation matrix by using the smallest sample size of 720, and found no substantial change in the overall conclusion or model fit. With the smallest sample size, the model fit was slightly better $(\mathrm{RMSEA}=.035, \mathrm{SRMR}=.020$; 


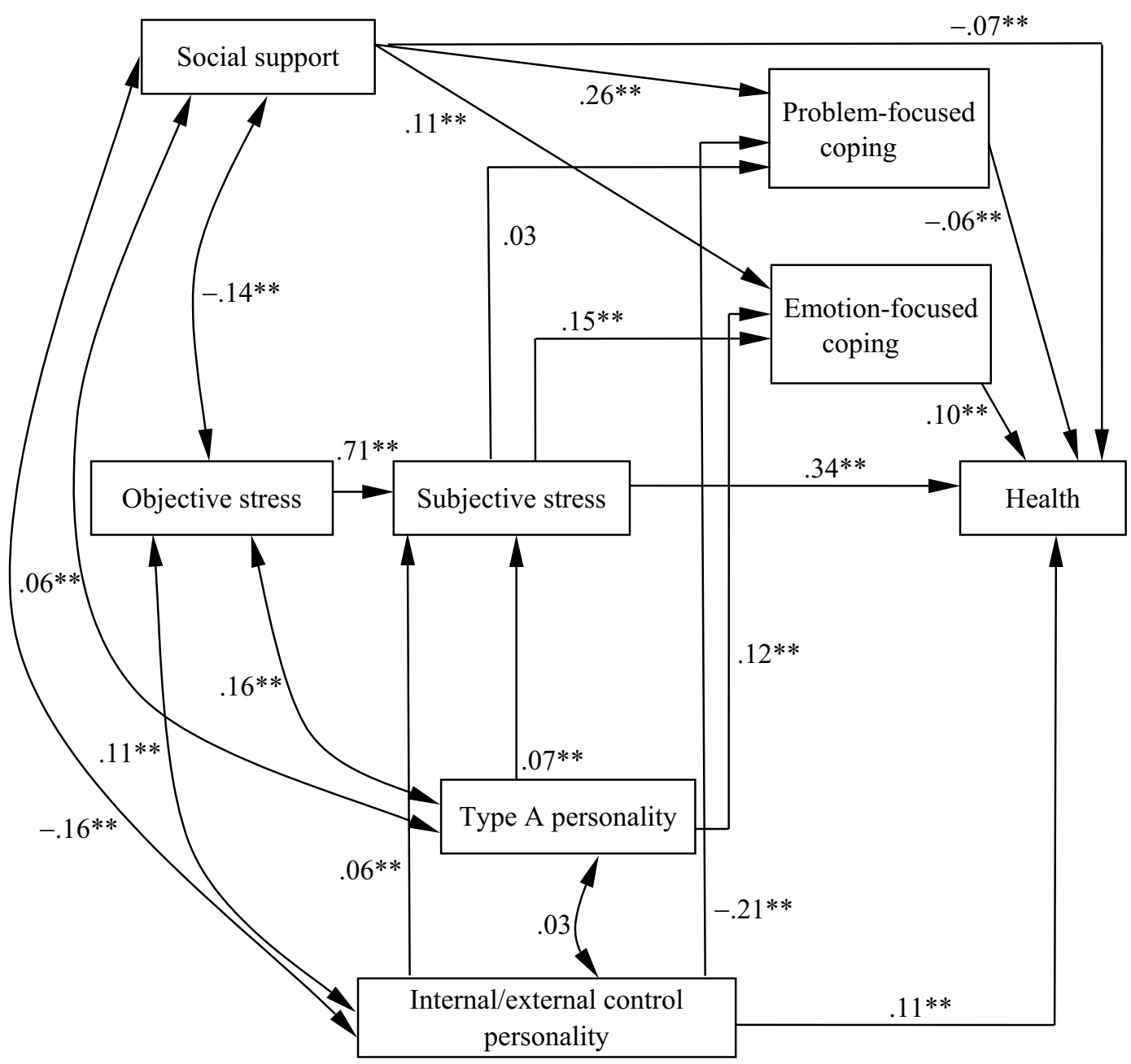

Figure 2. The revised theoretical stress-health model with standardized path coefficients. $\chi^{2}(8, N=4,745)=105.99, p<.001$; $\mathrm{SRMR}=.020 ; \mathrm{RMSEA}=.049 ; \mathrm{NNFI}=.94 ; \mathrm{IFI}=.98 ; \mathrm{RNI}=.98 ; \mathrm{CFI}=.98$. Standard errors for all path coefficients are around .01. Note. The higher the health score, the poorer the health condition. ${ }^{*} p<.01 .{ }^{* *} p<.001$.

$\mathrm{NNFI}=.97 ; \mathrm{IFI}=.99 ; \mathrm{RNI}=.99 ; \mathrm{CFI}=.99)$, and, while path coefficients remained the same, path coefficient significance became smaller. Path analysis with a large composite sample size could lead to statistically significant results that have no substantive or practical significance. Therefore, a statistical significance level of $p<.01$ is used throughout the following discussion, and, when path coefficients reach this significance level, those with absolute values less than .10 are interpreted as having no substantive effect or influence.

\section{Discussion}

The Role of Stress in the Stress-Health Process

Our study demonstrated that subjective stress has a significantly substantive and direct influence on health.
This finding is supported by the results of many recent studies (Lue et al., 2006; Rintala, Robinson-Whelen, \& Matamoros, 2005). Note that the insignificant path coefficient between objective stress and health was removed from the final model analysis. The finding supported the idea that a person's subjective feeling of stress or threat caused by external events has a much stronger influence on one's health than the event per se. Another finding that the path coefficient between objective stress and subjective stress was very high implied that subjective stress was an indispensable mediator factor for linking objective stress and health, which corresponded with the opinion of $\mathrm{Lu}$ (1997). In other words, the impact of events, even major life events, on one's health will be minute if one does not subjectively consider the event a threat or stress factor. 
Some objective stress events, such as examinations, heavy loading of work and assignments, and military service, are unavoidable. According to our study findings, the change or adjustment in one's feelings about stressful events will help to diminish the threat to his/her health.

Earlier studies in Taiwan (Huang \& Pai, 1992) defined subjective and objective stresses clearly. Recently, however, researchers (Weng, 2003) developing instruments for measuring stress have not distinguished clearly between the two. The reason could be that they paid greater attention to investigating the relationships between stress and other variables than to distinguishing between subjective and objective stress categories. However, while testing our stress-health theoretical model, we found that objective stress requires the intervention of subjective stress in order to impact health. This suggests that objective stress and subjective stress are different, and that it is proper to distinguish between these two in the development of future instruments.

\section{The Role of Coping Strategies in the Stress- Health Process}

The path coefficient between subjective stress and problem-focused coping strategies did not reach our designated level of statistical significance, indicating that subjective stress has an insignificant effect on problemfocused coping strategies. However, we found subjective stress to have a direct and substantive influence on emotion-focused coping strategies. This means that when one's subjective stress is high, he is likely to adopt emotionfocused, rather than problem-focused, coping strategies. Moreover, problem-focused coping strategies registered a positively direct, but not substantive, influence on one's health, whereas emotion-focused coping strategies had a negatively direct and substantive influence. In short, when subjective stress affects one's health through coping strategies, it is more likely to exert an adverse influence on one's health via emotion-focused coping strategies.

Some reviewers (Friedman, 2002; Wang \& Yeh, 2005) have suggested that emotions such as anxiety, nervousness, and anger emerge when we feel stress subjectively. When we are filled with these emotions, it is difficult to maintain the rational, logical judgment necessary for problemfocused coping. Instead, we will adopt emotion-focused coping strategies to adjust to such emotions. This viewpoint might partly explain the above finding. Furthermore, most of the emotion-focused coping strategies described in the primary studies reviewed neglected positive emotions. This might explain the finding in our study that emotionfocused coping has a negative influence on health. Folkman and Moskowitz's (2004) review highlighted the important relationship between positive emotional coping and health. They indicated that emphasis on the passive domain in dealing with emotions in most previous studies (e.g., engaging in distracting activities, using alcohol or drugs, seeking emotional support) could result in a negative influence on health. They further suggested that if studies turn to measure positive emotional coping (e.g., relaxation, positive reappraisal, situation redefinition, use of humor), different results may be obtained. This issue is worth investigating in future research.

Notably, according to Mullen and Suls's (1982) earlier meta-analysis, emotion-focused coping strategies benefited physical health more in the short-term and problem-focused coping strategies benefited physical health more over the long-term. Our study revealed the relationship between health and problem-focused or emotionfocused coping strategies to be comparatively weak. The reason could be that we directly combined the individual correlations between coping strategies and health without taking into account the different effects that length of stress continuity would have on the size of coping-health correlations. This fact may have weakened the correlations between coping strategies and health.

Some primary studies did not specify the time frame during which subjects rated their stress or health conditions on the self-report measurement scales. Although many primary studies did provide a time frame, most were not specific enough (e.g., "your stress condition from the first day you began this job until now" and "your life satisfaction from the beginning of your illness until now"). In such cases, the approximate time points on which the subjects' responses were based were not clear. Because of the above reasons, our study did not take time frame into account. This suggests that future research should specify a recent time period, for instance, "during the past one week" or "during the past one month," and use this time period as a time frame for periodic follow-up studies to obtain clear information about changes in stress and health with time.

\section{The Role of Social Support in the Stress- Health Process}

Social support was found to have a direct, but low and not substantive, effect on health. The direct effect of social 
support on health revealed that the higher the social support, the lower the health disturbance. This negative relationship finding corresponded to that of Wang et al. (2003). In Wang's meta-analysis, she divided the health construct into four facets and examined the relationship between social support and various health facets. In contrast, our study adopted a general health construct and revealed that social support had a lower relationship with health, as compared to Wang's.

In addition, social support had a direct and substantive effect on problem-focused and emotion-focused coping strategies. The path coefficient between social support and problem-focused coping strategies was larger than that between social support and emotion-focused coping strategies. This means that when higher social support (i.e., richer external resources) is available, it is much easier for people to adopt various coping strategies to manage the impact that the stress imposes on health, and people with higher social support tend to use problem-focused coping strategies more than emotion-focused coping strategies. Moreover, one's subjective feeling when receiving social support is drawing more and more attention (Li, 2000). As Li pointed out, what matters is not the quantity of social support (i.e., objective social support), but the timing and quality of such (i.e., subjective social support). In his review of the effects of social support on stress coping, Chiou (2001) also mentioned that many previous studies suggest increasing the quantity of social support. However, what matters is whether the recipients' needs for social support have been met.

Owing to lack of the correlation coefficients between subjective social support and Type A personality in the primary studies that we reviewed, this current study found it necessary to combine subjective and objective social support into a general social support construct in order to have complete data for use in SEM analysis. By so doing, the association between social support and stress or health may have been weakened. When sufficient data from primary studies are available in the future, the results obtained from investigating the roles that subjective social support plays in the relationship between stress and health will be more convincing.

\section{The Role of Personality Traits in the Stress- Health Process}

Both Type A and internal/external control personalities had a direct effect on subjective stress. This means that people with either one of these personalities tend to have higher subjective stress, although both direct effects are mild and not substantive. Further, the internal/external control personality was found to have a direct and substantive effect on health. Specifically, people with externalcontrol personalities tend to have health problems, while people with internal-control personalities tend to be optimistic and stay healthy. This finding has continuously been echoed in a number of recent studies (French, 2005; Takaki \& Yano, 2006). Those with an internal locus of control believe that they have control over their health and they can succeed at something they want to achieve (Pervin, Cervone, \& John, 2005; Rotter, 1966). Therefore, they are more likely than those with an external locus of control to take active measures to maintain their health and prevent illness (Sarafino, 2006). Moreover, our study found that the Type A personality had no direct effect on health. In contrast, Friedman and Rosenman (as cited in Gerrig \& Zimbardo, 2005; Sarafino, 2006) proposed that the Type A personality is a constellation of personality traits of patients with coronary heart disease. Our finding was unexpected and Sarafino's (2006) review of previous studies indicates that the relationship between the Type A personality and illness is still weak and inconsistent.

The direct effects that Type A and internal/external control personalities have on coping strategies are discrepant. This could result from differences in the nature of these two constructs. The internal/external control personality had a direct and substantive effect on problem-focused coping strategies, but not on emotion-focused coping strategies. On the contrary, the Type A personality had a direct and substantive effect on emotion-focused coping strategies, but not on problem-focused coping strategies.

Research (Park, Armeli, \& Tennen, 2004; Zakowski, Hall, Klein, \& Baum, 2001) has revealed that the greater the sense of personal control (i.e., internal controllers) people have when facing stress, the greater they will make use of problem-focused coping strategies. Bandura's concept of self-efficacy (1986) explained that internal controllers believe in their ability to solve problems and will plan ahead to prevent stress from getting out of control. This also reflects Rotter's concept of locus of control (1966), which consists of "expectancy" and "reinforcement value." Internal controllers, possessing high self-efficacy, expect that they will be able to do something which, in turn, will result in reinforcement value. This could explain our study finding that internal controllers, those with internal-control 
personality, might view stress as a challenge and thus often adopt problem-focused coping strategies.

As for the Type A personality, it is a complex pattern of behavior and emotions including being excessively competitive, aggressive, impatient, time urgent, irritable, easy to get upset, and hostile. Type A people seemingly keep dealing with the things they encounter. In fact, they keep dealing with the things in which they involve themselves. This appears to relate to their irritable, dysphoric emotions. The earlier meta-analysis by Suls and Wan (1989) confirmed the relation between Type A personality and irritable, dysphoric emotions. The behavior of Type A people may be the expression of such emotions or the expression of their attempts to alleviate the effect of such emotions. This is generally correspondent with the emotional reactions of people who adopt emotion-focused coping strategies to release stress. This might be the reason for the result of our study that people with Type A personalities tended to adopt emotion-focused coping strategies.

\section{Conclusions}

In recent years, issues related to stress management have received significant attention in the field of health care. Many suggestions related to stress reduction have been provided and many stress reduction experiences have been shared. These methods, in terms of objective stress, subjective stress, social support, coping strategies, and personality traits, are brought forth to improve the operating mechanism of the stress-health theoretical model and further to help us stay healthy.

Based on the theoretical stress-health model of this current study, subjective stress had a substantively important and direct effect on health, whereas objective stress needed the mediating function of subjective stress to exercise its influence. Such variables as social support, coping strategies, and personality traits had comparatively lower effects, either direct or indirect, in the stress-health process. To sum up, the most direct and best method for reducing the influences of stress on health is to adjust one's subjective feeling and appraisal of stress. This finding will provide an important reference for future intervention programs in health care to diminish the effects of stress on health. In other words, the results of our study imply that appropriate interventions in terms of social support, coping strategies, and personality traits can lessen the effects of stress on health. However, in order to effectively reduce the effects of stress on health, it is necessary to include the adjustment and improvement of personal subjective cognition and feelings in the design of stress management and intervention programs.

\section{Contributions and Limitations}

This current study was significant in two aspects. First, it integrated the various research findings in the literature on stress in Taiwan and estimated the aggregated correlations among stress, health, and various mediating or moderating variables. The second and major contribution of this study was that it demonstrated the adequacy of the proposed theoretical model to describe how stress influences health. The model shows different routes for the relationships among eight important constructs and can be used as a basis to test other modification variations. The use of meta-analytic path analysis to test both direct and indirect relationships in a theoretical model not only offers the reader the benefit of drawing conclusions aggregated from multiple studies, but also provides evidence to support causal interpretation of the relationships posited in the model. The merits of meta-analytic path analysis have been demonstrated in our study.

Although the current study has contributed to the synthesis and analysis of the literature on stress and the development of the stress-health model, there may be some limitations to the potential scope of contribution of this study. Because this study combined both subjective and objective social support in the analysis, it was not possible to distinguish the distinct roles that each play in the model. Another potential limitation comes from the small number of studies available for some of the analyses. For instance, the aggregated correlation between social support and the Type A personality was based on only a single study, making it more subject to sampling error and potentially less accurate. This reflects the situation that few primary studies conducted in the context of stress have examined both social support and the Type A personality in Taiwan. Moreover, when no study reporting a correlation between two variables of interest exists in the literature, researchers often must confine themselves to testing theories for which full matrices of correlations among variables can be found. This is a potential limitation for the approach of meta-analytic path analysis.

\section{Acknowledgment}

The authors would like to thank the National Science Council in Taiwan for funding this study (NSC 92-2413037-003). 


\section{References}

Aneshensel, C. S. (1999). Outcomes of the stress process. In A. V. Horwitz \& T. L. Scheid (Eds.), A handbook for the study of mental health: Social contexts, theories and systems (pp. 211-227). Cambridge, UK: Cambridge University Press.

Bandura, A. (1986). Social foundations of thought and action: A social cognitive theory. Englewood Cliffs, NJ: Prentice Hall.

Borenstein, M., Hedges, L., Higgins, J., \& Rothstein, H. (2005). Comprehensive meta-analysis: A computer program for research synthesis (Version 2.0). Englewood, NJ: Biostat.

Cheng, H. Y., Dai, Y. T., Kuo, S. H., \& Yao, K. P. (2000). Relationships between stress, coping strategies, and quality of life in adult asthma patients. The Journal of Nursing Research, 8(6), 599-613.

Chiou, W. B. (2001). The coping effect of social support: A critical review. Proceedings of the National Science Council: Humanities and Social Science, 11(4), 311-330.

Chu, L. C., \& Kao, S. R. (2005). The moderation of meditation experience and emotional intelligence on the relationship between perceived stress and negative mental health. Chinese Journal of Psychology, 47(2), 157-179.

Cohen, S., \& Wills, T. A. (1985). Stress, social support, and the buffering hypothesis. Psychological Bulletin, 98(2), 310-357.

Cox, T. (1978). Stress. Baltimore, MD: University Park Press.

Dahlin, M., Joneborg, N., \& Runeson, B. (2005). Stress and depression among medical students: A cross-sectional study. Medical Education, 39, 594-604.

Ding, L. (2003). The effect of the personality traits of MIS professionals to job stress. National Kaohsiung Hai Yuan Journal, 18, 211-225.

Diong, S. M., Bishop, G. D., Enkelmann, H. C., Tong, E. M. W., Why, Y. P., Ang, J. C. H., et al. (2005). Anger, stress, coping, social support and health: Modeling the relationships. Psychology \& Health, 20(4), 467-495.

Folkman, S., \& Moskowitz, J. T. (2004). Coping: Pitfalls and promise. Annual Review of Psychology, 55, 745-774.

French, J. (2005). Work locus of control as a moderating influence on the quality of work life for radiation therapists. Canadian Journal of Medical Radiation Technology, 36(1), 12-16.

Friedman, H. S. (2002). Health psychology (2nd ed.). Upper Saddle River, NJ: Prentice Hall.

Gerrig, R. J., \& Zimbardo, P. G. (2005). Psychology and life (17th ed.). Boston: Allyn \& Bacon.
Hammer, T. H., Saksvik, P. O., Nytro, K., Torvatn, H., \& Bayazit, M. (2004). Expanding the psychosocial work environment: Workplace norms and work-family conflict as correlates of stress and health. Journal of Occupational Health Psychology, 9(1), 83-97.

Hedges, L. V., \& Olkin, I. (1985). Statistical method for meta-analysis. Orlando, FL: Academic Press.

Hu, L. T., \& Bentler, P. M. (1999). Cutoff criteria for fit indices in covariance structure analysis: Conventional criteria versus new alternatives. Structural Equation Modeling, 6(1), 1-55.

Huang, H. C., \& Pai, L. (1992). A study on stress perception of adult life events. Proceedings of Medical Research of the Tri-Service Hospital, 15, 933-952.

Hunter, J. E., \& Schmidt, F. L. (2004). Methods of metaanalysis: Correcting errors and biases in research findings. Thousand Oaks, CA: Sage Publications.

Jiang, C. X. (1991). A correlational study on life stress, coping behaviors, and mental health of the adolescents. Unpublished master's thesis, National Taiwan Normal University, Taipei.

Jöreskog, K. G., \& Sörbom, D. (2004). LISREL 8.7: Computer software. Lincolnwood, IL: Scientific Software International.

Karlin, W. A., Brondolo, E., \& Schwartz, J. (2003). Workplace social support and ambulatory cardiovascular activity in New York City traffic agents. Psychosomatic Medicine, 65, 167-176.

Lazarus, R. S., \& Folkman, S. (1984). Stress, appraisal, and coping. New York: Springer.

Li, S. H. (2000). The study of everyday life stress, social support, and coping methods of low-income women: An example of Fu-Ming community. Unpublished master's thesis, National Yang Ming University, Taipei.

Liaw, G. F., Cheng, M. J., \& Wang, Y. S. (2005). A study of negative affectivity influencing the relationships among social support, stressor of role and job burnout. Journal of Human Resource Management, 5(4), 155-180.

Lipsey, M. W., \& Wilson, D. B. (2001). Practical metaanalysis. Thousand Oaks, CA: Sage Publications.

Lu, L. (1997). The process of work stress: A dialogue between theory and research. Formosa Journal of Mental Health, 10(4), 19-51.

Lue, B. H., Chen, H. J., \& Kao, M. Y. (2006). Perceived stress in medical students and its relationship to mental health. Journal of Medical Education, 10(1), 2533.

Matthews, G., Emo, A. K., Funke, G., Zeidner, M., Roberts, R. D., Costa, P. T., et al. (2006). Emotional intelligence, 
personality, and task-induced stress. Journal of Experimental Psychology: Applied, 12(2), 96-107.

Mills, L. J. (2000). Evaluation of a model of hardiness and health using meta-analysis and path analysis. Unpublished doctoral dissertation, University of Tulsa, Oklahoma.

Mullen, B., \& Suls, J. (1982). The effectiveness of attention and rejection as coping styles: A meta-analysis of temporal differences. Journal of Psychosomatic Research, 26(1), 43-49.

Ng, D. M., \& Jeffery, R. W. (2003). Relationships between perceived stress and health behaviors in a sample of working adults. Health Psychology, 22(6), 638-642.

Ogden, J. (2004). Health psychology: A textbook (3rd ed.). Buckingham Philadelphia: Open University Press.

Park, C. L., Armeli, S., \& Tennen, H. (2004). Appraisalcoping goodness of fit: A daily internet study. Personality and Social Psychology Bulletin, 30(5), 558-569.

Pearlin, L. I. (1999). Stress and mental health: A conceptual overview. In A. V. Horwitz \& T. L. Scheid (Eds.), A handbook for the study of mental health: Social contexts, theories and systems (pp. 161-175). Cambridge, UK: Cambridge University Press.

Pervin, L. A., Cervone, D., \& John, O. P. (2005). Personality: Theory and research (9th ed.). New York: John Wiley \& Sons.

Rintala, D. H., Robinson-Whelen, S., \& Matamoros, R. (2005). Subjective stress in male veterans with spinal cord injury. Journal of Rehabilitation Research \& Development, 42(3), 291-304.

Rotter, J. B. (1966). Generalized expectancies for the internal versus external control of reinforcement. Psychological Monographs, 90(1), 1-28.

Sarafino, E. P. (2006). Health psychology: Biopsychosocial interactions (5th ed.). New York: John Wiley \& Sons.
Smith, J. A. (1981). The idea of health: A philosophical inquiry. Advances in Nursing Science, 3, 43-50.

Suls, J., \& Wan, C. K. (1989). The relation between Type A behavior and chronic emotional distress: A metaanalysis. Journal of Personality and Social Psychology, 57(3), 503-512.

Takaki, J., \& Yano, E. (2006). Possible gender differences in the relationships of self-efficacy and the internal locus of control with compliance in hemodialysis patients. $\mathrm{Be}$ havioral Medicine, 32(1), 5-11.

Viswesvaran, C., \& Ones, D. S. (1995). Theory testing: Combining psychometric meta-analysis and structural equation modeling. Personnel Psychology, 48, 865-885.

Wang, H. F., \& Yeh, C. M. (2005). Stress, coping, and psychological health of vocational high school nursing students associated with a competitive entrance exam. The Journal of Nursing Research, 13(2), 106-116.

Wang, H. H., Wu, S. Z., \& Liu, Y. Y. (2003). Association between social support and health outcomes: A metaanalysis. Kaohsiung Journal of Medical Sciences, 19(7), 345-351.

Wasylkiw, L., \& Fekken, G. C. (2002). Personality and selfreported health: Matching predictors and criteria. Personality and Individual Differences, 33(4), 607-620.

Weng, C. C. (2003). A study of emotional exhaustion among local government accountants. The National Chi Nan University Journal, 6(2), 1-28.

Wheaton, B. (1999). The nature of stressors. In A. V. Horwitz \& T. L. Scheid (Eds.), A handbook for the study of mental health: Social contexts, theories and systems (pp. 176-197). Cambridge, UK: Cambridge University Press.

Zakowski, S. G., Hall, M. H., Klein, L. C., \& Baum, A. (2001). Appraisal control, coping, and stress in a community sample: A test of the goodness-of-fit hypothesis. Annals of Behavioral Medicine: A Publication of the Society of Behavioral Medicine, 23(3), 158-165. 


\title{
壓力與健康之模式驗證：統合徑路分析研究
}

\author{
余麗樺 邱兆宏* 林耀盛** 王秀紅*** 陳九五****
}

摘 要：本研究目的爲應用統合徑路分析技術以評估一壓力與健康之理論模式。本研究先採 用統合分析方法，結合國內於 1980 年 1 月至 2003 年 12 月間有關壓力議題之研究共 477 篇進行分析, 所蒐尋的資料庫包括「中華民國期刊論文索引系統」「全國博碩 士論文資訊網」「國科會科技資訊網路系統」。登錄的資訊包括壓力、健康、社會支 持、因應策略和人格特質等變項，從這些經過統合分析後的資料，獲得這些變項間 之相關矩陣, 然後再據之進行徑路分析, 以檢驗此壓力一健康之理論模式與得自實徵 研究之統合分析資料間的適配程度。研究結果顯示本研究所提出之壓力一健康理論模 式經修正後, 與統合分析資料之間有著良好的適配。就本研究整個壓力-健康理論模 式來看, 主觀壓力本身對健康具有實質且重要的直接效果, 而客觀壓力是需要透過 主觀壓力的中介作用, 才會對健康造成影響; 而社會支持、因應方式、人格特質等 變項, 在壓力一健康歷程中, 相較上不論是直接或間接, 都有著較小的影響。本研究 爲壓力和健康間的關係呈現出一個整體性的面貌, 並爲未來研究和實務工作提供可 參考的方向。

關鍵詞：壓力、健康、統合分析、徑路分析。

高雄醫學大學健康科學院副教授 *遠東科技大學學生輔導中心講師

**東華大學臨床與諮商心理學系

副教授 $\quad * * *$ 高雄醫學大學護理學院教授 $\quad * * * *$ 健康科學院副教授

受文日期：95 年 8 月 16 日 修改日期：96 年 3 月 7 日 接受刊載：96 年 6 月 20 日

通訊作者地址 : 陳九五 80708 高雄市三民區十全一路 100 號 